on "Continuous Calculating Machines," in the Philosophical Transactions of the Royal Society, part ii., 1885 .

This note, whilst giving due priority to M. Ventosa in the matter of one of the two features of the sphere and roller integrator, described in the above paper, a feature at which I need scarcely say I arrived quite independently, points to the fact that this forms but a part of the integrator in question. When combined with the other portion, that integrator is a calculating machine in the widest sense of the term. I have shown that in addition to giving the value of

$$
\int y d x
$$

where $y$ is any linear function of $x$, other varieties of the mechanism obtain the value of such expressions as

$$
\int F_{1}(x) F_{2}(x) \ldots F_{\mathrm{n}}(x) d x
$$

and

$$
\iint \phi(x, y) d y d x
$$

and also by a converse process give approximately the value at any instant of $R$ where

$$
R=\frac{d y}{d x} .
$$

I had not before to day seen the paper of Mr. F. J. Smith in the Phil. Mag. (August I886), referred to by M. Ventosa. On pp. 381 and 382 of my paper above alluded to will be found a description of an integrator which is practically identical with that of Mr. Smith, as I have no doubt he will admit when he reads that description. With that integrator hollow brass balls were employed for the very purpose suggested by $\mathrm{Mr}$. Smith. The instrument was, however, abandoned in favour of more convenient forms, one of which was actually employed by that gentleman upon his "ergometer" at the Inventions Exhibition, together with some very ingenious integrators of his own design. There is, I would say, one point of difference between the integrator described by Mr. Smith, and that by myself. The movable arm in the former appears to be guided by a pin in a straight slot. Now in the "sine" form, of which this intesrator is an example, this pin should move in the arc of a circle, and it would be interesting to know if approximately correct results have been obtained with what is in some respects a more convenient practical device.

University College, Liverpool, April 9

$$
\text { H. S. HELE SHAw }
$$

\section{The Vitality of Mummy Seeds}

I READ with much surprise in NATURE of March 31 (in Prof. Judd's defence of his statement as to the longevity of seeds) that "competent botanists have cited the case of the germination of seeds taken from ancient Egyptian tombs as authentic." Many experiments have been made as to the length of time seeds may retain their power of germinating, by Robert Brown, Henslow, and others, with interesting result; as to the longevity of some; but my impression is, and I venture to make it public, that competent botanists have universally condemned as utterly worthless the evidence given in support of alleged instances of the germination of mummy seeds. No scientifically responsible person has, so far as I am aware, put the fact on record. In these circumstances, therefore, the results of the successful experiments referred to farther on by Prof. Judd as having recently been made, possess the greatest interest, and botanists will look forward eagerly to the details which it is to be hoped will soon be made public. Hitherto the fruitful source of error has been the deception at the outset of the credulous experimenter by the Arab. In fact, the mummy wheat of one welk-known traveller grew up in the form of oats--a plant not cultivated by the ancient Egyptians, but now grown in the land they inhabited-though this did not shake his faith in the genuine sou:ce of his supply. In the present case, however, the statement made in faith by so high an authority as Prof. Judd leads us to anticipate that the undertakin $r$ has been hedged in with all the safeguards demanded by a pure cultivation of undoubtedly genuine material.

7 Onslow Place, South Kensington, S.W., A pril 5

\section{Solar Halos}

In the forenoon of March 6 the sun was surrounded by a series of halos of the form shown in the diagram. The side of each arc, marked with a wavy or saw-toothed outline, was red, and the opposite edge blue; but no colour at all was visible in the horizontal belt nor in the farthest-out halo $\left(\mathrm{H}_{3}\right)$. This sketch shows the appearance at about $9 \mathrm{a} . \mathrm{m}$.; as the sun rose higher, the horizontal belt got a curve upwards at each sidei.e. it continued to be parallel to the horizon-and was prolonged inside $\mathrm{H}_{1}$ till it almost touched the sun. The two mock-suns

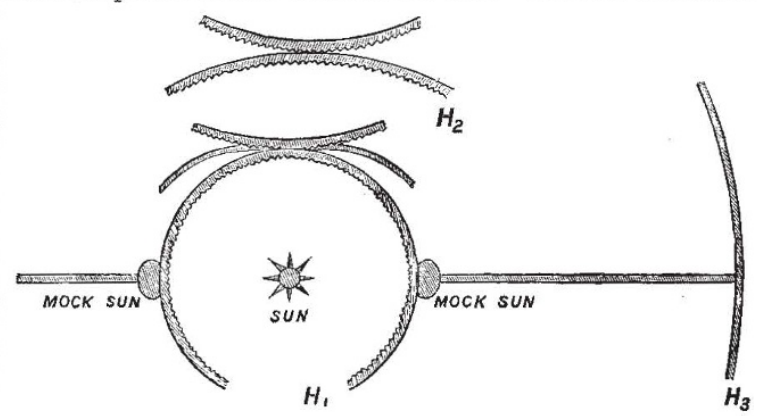

were distinctly on the outside of $\mathrm{H}_{1}$, and were coloured red next the sun, and blue outside, their reds about coinciding with the blue of $\mathrm{H}_{1}$. The following are some of the measurements :-

$$
\begin{array}{rlllllll}
\text { Sun to western mock-sun } & \ldots & \ldots & \ldots & \ldots & \mathbf{2 3} & 46 \\
,, & \text { eastern }, & \ldots & \ldots & \ldots & \ldots & \mathbf{2 3} & 42 \\
,, & H_{3} \text { (two measurements) } & \ldots & \ldots & \ldots & 79 & 56 \\
8 \mathbf{I} & 23
\end{array}
$$

The halo $\mathrm{H}_{3}$ has, I believe, been very seldom seen, and there are only three estimates of its radius on record: two of these make it $90^{\circ}$, and the third makes it $85^{\circ}$ to $90^{\circ}$. It will be seen that our measurements-both about $8 \mathrm{I}^{\circ}$-are considerably less than any of the former ones, R. T. OMOND

Ben Nevis Observatory

\section{On the Character of the Beds of Chert in the Carboniferous Limestone of Yorkshire}

IT may be of interest to geologists to know that $I$ have lately ascertained that the beds of chert which occur in the limestones of the Yoredale series of Yorkshire are distinctly of organic origin, and that, in fact, they are composed of the heterogeneously-mingled spicules of disintegrated siliceous sponges. The beds vary from 3 inches to 18 feet in thickness, and the limestones in. which they are interbedded are nearly exclusively composed of the broken-up remains of crinoids, thus showing a well-marked alternation of periods in which sponges and crinoids succeeded each other. The spicules can only be studied in thin microscopic sections of the rock; in some cases they are very perfectly preserved and their axial canals are clearly shown; in other examples only very faint outlines can be made out. They appear to belong for the most part to the same group of Hexactinellid sponges as the recent genus Hyalonema, but Monactinellid spicules, like those of the existing genus Reniera, are also very numerons in some of the beds. Such an enormous accumulation of the debris of siliceous sponges proves that these organisms were as abundant in the Carboniferous as in the Cretaceous seas

The beds of chert referred to are exposed near Harrogate, and at Richmond, Yorkshire, and they are remarkably developed at Arkendale, about fourteen miles above Richmond. I am indebted ts Mr. J. G. Goodchild, of the Geological Survey, for directing my attention to this last-named locality. Owing to their resistant character, fragments of the beds are also widely distributed in the boulder-clays to the south of their outcrops, and I have met with them in these clays near York.

It has been known for some time that the remains of siliceous sponges are of comnon occurrence in the Carboniferous chert beds of Ayrshire and of certain parts of Ireland, but they do not appear to have been noticed hitherto in the corresponding beds of Yorkshire. I hope shortly to give a more detailed description of their principal characters.

Croydon, April 2 